\title{
Going all the way with B.J.
}

\section{Canberra}

THE 54th Congress of ANZAAS, the Australian and New Zealand Association for the Advancement of Science, was held amid the fading autumn colours and falling leaves of the spaced-out campus of the Australian National University. For five days from 14 May, the congress generated wide coverage of popular items in the press and on radio. Yet the congress lacked the focus promised by the stated theme of "Horizons of Science". The congress was woolly at the edges and soft at the centre.

For decades, the peripatetic congress has struggled to resolve the inherent tension of providing both parallel specialist meetings and cross-disciplinary exchange. Other conflicts surfaced again, notably the confusion about objectives. Is ANZAAS primarily seeking to communicate the latest results, ideas and challenges in science to the wider public and, incidentally, to persuade politicians of the importance and relevance of science? Or is the event principally for academic discourse? At Canberra, neither promise was fulfilled.

Among the 1,600 delegates - a big drop from earlier meetings but still the largest meeting on the Australian academic calendar - were relatively few who had come to listen and to discuss. With more than 1,000 papers being delivered, the speakers outnumbered others. People from outside the academic or research spheres were notably absent. To reach the public at large, or even groups such as schoolteachers and students, ANZAAS relies entirely on journalists.

The trend away from science and technology towards the social sciences and humanities continued. Of the 33 specialized sections, only 15 were devoted to the sciences and technologies, and some were pitifully weak.

The "Horizons of Science" theme, only dimly reflected in the congress programme, was almost totally ignored by individual speakers. Thus a showcase for the current state of Australian science was left empty. But some of the congress-wide symposia produced fruitful discourse, tackling issues of current concern in Australia which as exotic diseases, science and political decisions, technology strategy and nuclear arms. The last, with Petra Kelly and retired General Gert Bastian, parliamentary members of the West German Green Party as visiting attractions, was the best attended, reflecting the growth of the peace movement in Australia.

This symposium even produced a collective statement by a working group on the effects of the British nuclear tests carried out in the Australian desert between 1952 and 1963. Allegations of a cover-up by the British of aspects of these tests have become the centrepiece of a major diplomatic row between the Australian and British Governments and the rallying point for anti-nuclear protests in Australia. The ANZAAS group called on the Australian Government to conduct a comprehensive interdisciplinary study of the effects of the British tests, saying that a committee formed by the Department of Resources and Energy is inadequate.

ANZAAS was not entirely at odds with the federal government, however. Professor Sir Gustav ("Gus") Nossal, this year's president, gave one of the most glowing tributes to a politician by a scientist in recent times. An immunologist and director of the Walter and Eliza Hall Institute for Medical Research in Melbourne, he solidly backed the discussion draft released in April by Mr Barry Jones, Minister for Science and Technology (see Nature 3 May, p.6).

The draft, he said, was "the most significant and courageous document to come out of Canberra on any topic in the past decade'". The ANZAAS president went on to urge that the minimum realistic incentive for industry to increase its commitment to research and development would be a tax credit of 150 per cent.

Sir Gustav saw "the most significant, marvellous and stunning element" in the technology strategy draft as being the proposals for achieving 50 per cent completion of secondary school (from 36 per cent now) and 20 per cent of tertiary education (a doubling of the present figure) by 1995 . While critical of the emphasis on the quantity of education and of the view that the draft was "singularly silent on quality", Nossal hs put his reputation on the line as an influential backer of Jones.

Not everybody in Canberra approved. Professor Gordon Reid, until recently at the University of Western Australia and soon to be governor of the state, said Sir Gustav's statement was not based on scientific inquiry and accused him of "exercising hyperbole in his role as president".

Professor Reid said Sir Gustav's statement was an example of the ambivalence of Australian science. In one breath, he said, scientists plead for freedom from government direction, and in the next for more financial support.

Nossal is unrepentant. "A tremendous challenge is faced by the Australian scientific community to explain ourselves better. . . and to promote a technological culture. We scientists should inform the public about what we are doing, about what practical results can realistically be expected, and about what longer-term dreams can legitimately be espoused."

Later, he complained of "the besetting sins of Australian scientific academics of treating PhD students as clones of themselves and of shunning applied orientations for their research". He asked university administrators to treat their relations with the media and the public "seriously and as a sacred duty".

By defining its role in terms of facilitating communications among scientists and between scientists and the public, ANZAAS might be expected to take a lead in solving the problems posed by its current president. In reality, ANZAAS has little to offer between congresses as its central organization is weak and strapped for cash (it receives no government support and has fewer than 3,000 subscribing members).

However, bold plans for change were announced by the organiizers of the next congress, to be held in Melbourne in August 1985 . They will virtually abandon the specialized sections and, through a broad grouping of interests under seven headings, will redirect their offerings to young people and the general public (both of which groups were noticeably absent from the Canberra congress) while attracting scientists to interdisciplinary sessions which will explore the current "state of the art" and identify promising new directions.

Peter Pockley

\section{Nature banned (1937)}

As part of the continuing availability of German documents of the 1930 s, it has come to light that the National Socialist government issued a decree, circulated to all university and research libraries, requiring that copies of Nature should not be made generally available. Moreover, the decree required that its own existence should be secret.

The text of the decree, dated 12 November 1937, is as follows:

Articles are often published in the London weekly scientific journal Nature containing outrageous and vile attacks on German science and the national socialist state. The journal must therefore be excluded from general use in scientific libraries. I request the university, academies, institutes and seminar libraries to carry out the appropriate steps. Regarding the sequestration and restricted use of the journal I refer to my decrees of 17 September 1934, 3 April 1935 and 16 December 1936, UI 22733, W Ie 828 and W la 2305.

The decree is signed by the Imperial and Prussian Minister for Science, Education and Development and no doubt refers to the continuous stream of hostile comment appearing in Nature in the mid-1930s, much of it centring around the work of the Academic Assistance Council formed in 1933 to help German academics to find posts overseas. Thus in July 1937, Nature $(140,169 ; 1937)$ referred to the dismissal of German Jewish academics as the "German disaster" 'and remarked that it was unlikely that "the leaders of intolerance and irrationalism will be deterred by the knowledge that their victims will be sheltered in the asylum of liberal countries". 